\title{
NILAI BUDAYA DAN MORAL DALAM TRADISI (LISAN) MUAYAK PADA ACARA SUNATAN MASYARAKAT BANDING AGUNG OKU SELATAN (SUMATERA SELATAN)
}

\section{CULTURAL AND MORAL VALUES IN MUAYAK TRADITIONS IN SUNATAN EVENT BANDING AGUNG COMMUNITY SOUTH OKU (SOUTH SUMATERA)}

\author{
Erwanto $^{1 *}$, Emilia Contessa ${ }^{2}$ \\ Pendidikan Bahasa dan Sastra Indonesia, Universitas Baturaja, Indonesia ${ }^{1,2}$ \\ erwantow420@gmail.com ${ }^{1}$, emiliacontessa84@gmail.com ${ }^{2}$ \\ *penulis korespondensi
}

\begin{tabular}{ll}
\hline Info Artikel & ABSTRAK \\
\hline Sejarah artikel: & Sastra daerah merupakan bagian dari suatu tradisi dan budaya warisan \\
Diterima: & nenek moyang yang harus kita lestarikan. Salah satu budaya lokal yang \\
8 Februari 2020 & harus dilestarikan oleh generasi penerusnya adalah tradisi lisan muayak \\
Direvisi: & yang berasal dari Banding Agung OKU Selatan. Budaya lokal tersebut \\
8 Mei 2020 & diciptakan oleh masyarakat ranau dengan daya kreativitas yang dituntut \\
Disetujui: & untuk melahirkan pengalaman batin. Bahkan dijadikan sebagai pengalaman \\
18 Juni 2020 & hidup masyarakat ranau yang pada hakikatnya merupakan bagian dari seni \\
& yang berusaha menampilkan nilai-nilai keindahan yang bersifat aktual dan \\
Kata kunci: & imajinatif yang berhubungan dengan renungan terhadap berbagai macam \\
Nilai budaya, & problema yang berhubungan dengan manusia. Tujuan penelitian ini adalah \\
nilai moral, & untuk mendeskripsikan nilai-nilai budaya dan moral yang disampaikan \\
tradisi, Muayak & dalam tradisi (lisan) muayak pada acara sunatan masyarakat Banding \\
& Agung OKU Selatan. Penelitian ini menggunakan pendekatan kualitatif \\
& dengan metode deskriptif. Sumber data adalah rekaman tradisi (lisan) \\
& muayak. Teknik pengumpulan data adalah teknik dokumentasi. Untuk \\
& menganalisis data, penulis menggunakan teknik analisis karya. Berdasarkan \\
& hasil analisis disimpulkan bahwa nilai budaya terdiri dari nilai budaya \\
dalam hubungan manusia dengan Tuhan, nilai budaya dalam hubungan \\
manusia dengan manusia lain, nilai budaya dalam hubungan manusia \\
dengan masyarakat, nilai budaya dalam hubungan manusia dengan alam, \\
dan nilai budaya dalam hubungan manusia dengan dirinya sendiri. \\
Selanjutnya, nilai moral terdiri atas nilai moral religius, nilai moral pribadi, \\
dan nilai moral sosial.
\end{tabular}

\begin{tabular}{ll}
\hline Article Info & ABSTRACT \\
\hline $\begin{array}{l}\text { Article history: } \\
\text { Received: }\end{array}$ & $\begin{array}{l}\text { Local literature is part of a tradition and cultural heritage that we must } \\
\text { preserve, one of the local cultures that must be preserved by the next }\end{array}$ \\
8 February 2020 & generation is the oral tradition of Muayak originating from Banding Agung \\
Revised: & OKU Selatan The local culture was created by the Ranau community with \\
8 May 2020 & the creativity which is required to create the inner experiences, but more \\
Accepted: & than that as the life experience of the Ranau community which is essentially \\
18 June 2020 & part of art that eager to display the values of beauty that are actual and \\
& imaginative that are associated with reflections on various kinds of problems \\
& related to humans. The purpose of this study is to describe the cultural and \\
& moral values conveyed in the oral (oral) tradition at the circumcision of the \\
Keyword: & Banding Agung OKU Selatan. This research uses a qualitative approach \\
cultural values, & with descriptive methods. The data source is a recording of the oral tradition. \\
moral values, & The data collection technique is a documentation technique. To analyze the \\
traditions, Muayak &
\end{tabular}


data, the writer used the work technique analysis. Based on the results of the analysis concluded that cultural values consist of cultural values in human relations with God, cultural values in human relations with other humans, cultural values in human relations with society, cultural values in human relations with nature, and cultural values in human relations with him itself. Furthermore, the moral values which consist of religious moral values, personal moral values, and social moral values.

\section{PENDAHULUAN}

Negara Indonesia merupakan negara bhineka tunggal ika yang dikenal sebagai negara kepulauan yang mempunyai bahasa, budaya, dan sastra. Sastra bersifat imajinatif, estetik dan menyenangkan. Sastra diciptakan sepanjang sejarah kehidupan manusia. Hal itu disebabkan manusia memerlukan karya sastra sebagai media hiburan yang memberikan manfaat pada kehidupan khususnya pada sastra daerah. Hal ini sejalan dengan pendapat Nurhayati (2012:3) yang menyatakan bahwa sastra merupakan suatu karya yang menyampaikan suatu jenis pengetahuan dengan memberikan kenikmatan unik dan pengetahuan untuk memperkaya wawasan pembacanya. Salah satu sastra nusantara adalah sastra daerah. Muayak merupakan sastra daerah dari suatu tradisi lisan dan budaya warisan nenek moyang yang harus dilestarikan. Sastra lisan yang ada di Nusantara yang perlu dipelihara dan dilestarikan karena sastra lisan bagian dari kebudayaan bangsa yang masih hidup dan memegang peranan untuk pengembangan sastra Indonesia. Endraswara (2008:151) mengemukakan bahwa sastra lisan yang hidup dan berkembang pada masyarakat pemakainya merupakan bagian yang tak terpisahkan dari pola hidup dan perkembangan budaya masyarakat itu. Keanekaragaman corak hidup, pola pikir, dan peradaban masyarakat biasanya akan tercermin dari produk sastra yang muncul pada zamannya. Oleh karena itu, sastra lisan atau tradisi lisan memiliki ciri-ciri tertentu yang membedakan dengan sastra modern pada umumnya. Untuk itu, sastra daerah yang merupakan gambaran alam budaya bangsa Indonesia perlu dilestarikan dan dikembangkan dalam menunjang perkembangan bahasa dan budaya. Budaya terdiri dari segala sesuatu yang dipelajari dari pola-pola perilaku yang mencakup segala cara atau pola pikir, merasakan dan bertindak. Budaya juga dapat berbentuk fisik seperti halnya seni yang dapat juga berbentuk kelompok masyarakat atau lainnya. Sebagai realitas objektif yang diperoleh dari lingkungan dan tidak terjadi dalam kehidupan manusia terasing, melainkan dalam kehidupan suatu masyarakat.

Herimanto, dkk (2008:29) mengemukakan kebudayaan adalah hasil cipta, rasa, dan karsa manusia. Manusia yang beretika akan menghasilkan budaya yang memiliki nilai-nilai etika pula. Etika berbudaya mengandung tuntunan bahwa budaya yang diciptakan manusia bersifat universal atau diterima sebagian besar orang. Selanjutnya, Kosasih (2012:3) mengemukakan bahwa karya sastra tidak lepas dari nilai-nilai budaya, 
sosial ataupun moral. Nilai-nilai budaya berkaitan dengan pemikiran, kebiasaan dan hasil karya cipta manusia. Hal tersebut sesuai dengan pendapat berikut ini.

Pada hakikatnya, sastra merupakan bagian dari seni yang berusaha menampilkan nilai-nilai keindahan yang bersifat aktual dan imajinatif sehingga mampu memberikan hiburan atau kepuasan rohani pembaca. Selain mengandung nilai-nilai keindahan, sastra juga mengandung pandangan yang berhubungan dengan renungan atau kontemplasi terhadap berbagai macam problema yang berhubungan dengan manusia, seperti nilai agama, pendidikan, filsafat, dan kebudayaan (Aminuddin, 2010:37).

Sastra lisan yang ada di Nusantara yang perlu dipelihara dan dilestarikan adalah muayak. Muayak merupakan salah satu warisan budaya dan sastra lokal yang terdapat di Kabupaten OKU Selatan (Sumatera Selatan) yang di dalamnya terkandung nilai kearifan budaya lokal yang dapat dijadikan pelajaran atau pedoman hidup manusia yang responsif terhadap sesuatu yang luhur dalam hidup. Hal tersebut sependapat dengan Mahyana (2005:36) yang mengemukakan bahwa pengarang dan pembaca sama-sama menduduki posisi yang penting. Membaca karya sastra besar juga dapat menolong pembacanya menjadi manusia yang berbudaya. Manusia yang berbudaya adalah manusia yang responsif terhadap apa-apa yang luhur dalam hidup ini. Manusia demikian itu mencari nilai-nilai kebenaran.

Fokus penelitian ini, hanya pada muayak acara sunatan atau khitanan. Peneliti menganggap perlu meneliti muayak yang dibawakan oleh bebay baya karena sering digunakan dalam setiap acara pada ritual nayuh sunatan atau khitanan. Masalah dalam penelitian adalah apa saja nilai budaya dan nilai moral yang terkandung dalam tradisi (lisan) muayak pada acara sunatan masyarakat Banding Agung OKU Selatan. Penelitian ini bertujuan untuk mendeskripsikan nilai-nilai budaya dan moral yang disampaikan dalam tradisi (lisan) muayak pada acara sunatan masyarakat Banding Agung OKU Selatan.

\section{METODE}

Penelitian ini menggunakan pendekatan kualitatif dengan metode deskriptif. Metode deskriptif menurut Surahkmad (2004:131) metode merupakan cara utama yang digunakan untuk mencapai suatu tujuan, misalnya untuk menguji serangkaian hipotesa, dengan mempergunakan tekhnik serta alat-alat tertentu. Sumber data diperoleh dari rekaman tradisi (lisan) muayak pada acara sunatan masyarakat Banding Agung OKU Selatan. Teknik pengumpulan data yang peneliti gunakan dalam penelitian ini adalah menggunakan teknik dokumentasi. Dokumentasi adalah catatan peristiwa yang sudah berlalu. Bisa bentuk lisan, gambar, atau karya-karya menumental dari seseorang (Sugiyono, 2013:240). Untuk menganalisis data, penulis menggunakan teknik analisis karya. Menurut Nurgiyantoro (2010:31), analisis karya fiksi yaitu penelaahan, penyelidikan yang merupakan perbendaharaan dari pembuatan, mengkaji, menelaah, mengurai karya.

\section{HASIL DAN PEMBAHASAN}

Muayak ini dilaksanakan pada acara sunatan nanda Hakam bin Peldi Yusron dan Nanda Aam bin Reza 
Fahlevi, dan Budiom lamban Bandakh Batin Dalom Gusti Cakra Buana (kampung Tengah) di Banding Agung Ranau OKU Selatan tanggal 1-3 Agustus 2014. Berikut wujud salah satu dokumentasi kegiatan.

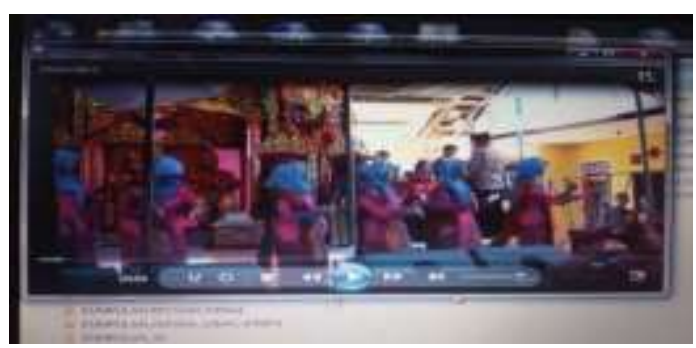

Gambar 1 Wujud Kegiatan

Menurut Kosasih (2012:46), Nilai budaya berkaitan dengan pemikiran, kebiasaan, dan hasil cipta karya manusia. Nilai budaya ini mencakup semua nilai-nilai yang ada di dalam karya sastra itu sendiri. Selanjutnya, Mangkuprawira, (2006:1) mengemukakan bahwa nilai moral meliputi nilai moral religius, nilai moral pribadi, dan nilai moral sosial.

Berdasarkan hasil analisis diketahui bahwa dalam muayak pada acara adat tradisi (lisan) masyarakat Banding Agung yang dilaksanakan pada salah satu acara nayuh terdapat nilai budaya dan nilai moral yang dapat dijadikan sebagai pedoman dalam kehidupan.

\section{Nilai Budaya}

Nilai budaya hubungan manusia dengan tuhan tergambar pada kata assalammualaikum, kata assalamualaikum merupakan ucapan yang selalu dilakukan oleh pemeluk agama Islam atau umat muslim ketika berjumpa dengan orang lain, hal ini merupakan kepercayaan dan keimanan pada agama yang dianut. Selanjutnya, kata budua merupakan permohonan terhadap keinginan manusia kepada
Tuhan pencipta alam. Sehingga makna kata budua termasuk ke dalam hubungan manusia dengan Tuhan.

Nilai budaya dalam hubungan manusia dengan manusia lain berdasarkan kutipan sunyini sai wat dija mempunyai makna orang-orang yang berkumpul dengan tujuan memperarat tali silaturahim antar manusia yang satu dengan yang lain sehingga terjalin hubungan yang baik dengan orang lain. Hal tersebut diperkuat dengan kutipan sekam jak pihak kelama, pengisini nyak Nari yang mempunyai arti kami dari pihak famili keluarga, mengisi acara. Selanjutnya, jalinan silaturahim dan hubungan baik dengan sesama orang lain diperkuat dikutipan tanno ngumpul didija, lain pungawoh hanjak. Tanno ngumpul didija, mempunyai makna berkumpul bersama di sebuah acara dengan tujuan untuk lebih mempererat hubungan silaturahim dengan orang lain terutama keluarga.

Nilai budaya dalam hubungan manusia dengan alam Alam dengan segala situasi dan kondisinya merupakan tempat manusia hidup. Berdasarkan kutipan Ija ram namon cabi, Dang lupa kawai halom, (di sini kita Menanam Cabe, jangan lupa pakai baju hitam). Menggambarkan hubungan manusia dengan alam, yang bermakna dimana kita sebagai manusia membutuhkan alam sebagai tempat untuk mendapatkan hasil-hasil alam, sehingga menjadi sesuatu yang berguna bagi kehidupan kita. Kutipan tersebut diperkuat lagi pada kalimat dipekon nanom tebu, nanom dihimalaya (didesa menanam tebu, menanam di Himalaya) kutipan dipekon nanom tebu ini bermakna bahwa alam merupakan tempat untuk menghasilkan sumber kehidupan berupa hasil bumi, sedangkan pada kata nanom dihimalaya 
merupakan makna kata tanah yang amat subur, kata kias Himalaya adalah tempat yang bersalju, bersalju berarti sejuk, sejuk berarti dingin, kata dingin ini mempunyai makna kata tempat dan tanah yang subur.

Nilai budaya dalam hubungan manusia dengan dirinya sendiri, kita sebagai manusia harus menjaga sikap dan perbuatan agar kita dianggap manusia yang utuh dan memiliki tanggung jawab dalam dirinya. Berdasarkan kutipan kintu wat cawacawa, dari kutipan di atas dapat disimpulkan bahwa makna kata kintu wat cawa-cawa, maaf jama sunyini mempunyai makna keseluruhan bahwa kita sebagai manusia harus menjaga sikap, cara bicara, tingkah laku agar kita dianggap manusia yang utuh dan memiliki tanggung jawab dalam dirinya sendiri.

\section{Nilai Moral}

Nilai moral religius dapat dilihat pada kalimat assalammualaikum pembukaani cawa mengandung makna merupakan nilai kerohanian tertinggi dan kepercayaan manusia terhadap Kaidah kehidupan yang beriman, pengucapan salam di awal perjumpaan dan pembicaraan pada seseorang yang memiliki sikap religius. Nilai religius diperkuat lagi pada kutipan sekam maklamon ngusung, selain anjak dua. Acara repa sinji, Sunatan ram bedua. Payu neram budua, minak muari sunyini Barong neram budua, sihat munyai adek ji kata bedu'a pada setiap akhir kalimat mempunyai makna permintaan atau permohonan manusia kepada yang maha kuasa, penyerahan diri bahwa segala sesuatu penentunya hanya Tuhan yang Maha Kuasa.

Nilai moral pribadi berhubungan erat dengan tata kelakuan individu (manusia) yang berhubungan dengan dirinya sendiri dalam bersikap dan berperilaku untuk menjadikan dirinya bermanfaat dan berguna. Kutipan Kintu wat cawa-cawa, maaf jama sunyini menggambarkan ungkapan permohonan maaf apabila dalam ucapkan atau kata-kata yang kurang berkenan dihati para pendengar, ungkapan kata-kata yang secara tidak langsung merupakan sebuah tindakan atau prilaku seseorang yang mengarah kepada sopan atau tidak sopan. Perilaku yang tidak berkenan diperkuat dengan kutipan sekam ngisi acara,pakotni guwai pagi. makna kata yang mungkin ketika dalam mengisi acara ada hal-hal atau perbuatan yang kurang berkenan sehingga menyinggung perasaan orang lain pada saat acara hajatan sunatan. Berdasarkan penjelasan analisis kutipan di atas, sangat jelas menunjukkan tata kelakuan individu manusia yang berhubungan dengan dirinya sendiri dalam bersikap dan berperilaku sebagai suatu moralitas kepribadian yang luhur untuk menjadikan dirinya bermanfaat dan berguna bagi orang lain.

Nilai moral sosial merupakan aspek kehidupan sosial masyarakat terdapat berbagai golongan dan aliran yang beraneka ragam, yang menjadi pedoman bagi segala pergaulan kehidupan sehari-hari sehingga kepentingan masing-masing anggota masyarakat terpelihara dan terjamin. Pada kalimat Nyak haga sai ketiku, sunyini sai wat dija, sekam jak pihak kelama, pengisini hanari. Kata sunyini sai wat dija mengandung kumpulan saudara, tetangga dan keluarga merupakan aspek kehidupan sosial masyarakat terdapat berbagai golongan dan aliran yang beraneka ragam. Kalimat tersebut diperkuat lagi dengan sekam jak pihak kelama, pengisini hanari, kalimat ini mengandung makna 
acara sunatan merupakan bentuk pergaulan kehidupan seseorang atau kelompok masyarakat sehari-hari di lingkungan anggota masyarakat yang terpelihara dan terjamin yang berhubungan dengan kaidah atau norma-norma sopan-santun, tata krama dan etiket. Kaidah-kaidah hukum yang tertuju kepada terciptanya ketertiban, kedamaian dan keadilan dalam kehidupan bersama atau bermasyarakat yang penuh dengan kepastian atau ketenteraman.

\section{PENUTUP}

Berdasarkan hasil analisis data dan pembahasan tradisi (lisan) muayak pada acara sunatan masyarakat Banding Agung dapat disimpulkan bahwa dalam muayak ini terdapat nilai budaya dan nilai moral. Nilai budaya terdiri dari nilai budaya dalam hubungan manusia dengan Tuhan, nilai budaya dalam hubungan manusia dengan manusia lain, nilai budaya dalam hubungan manusia dengan masyarakat, nilai budaya dalam hubungan manusia dengan alam, dan nilai budaya dalam hubungan manusia dengan dirinya sendiri, selanjutnya nilai moral yang terdiri dari nilai moral religius, nilai moral pribadi, dan nilai moral sosial.

Penelitian ini diharapkan dapat menambah ilmu pengetahuan bagi pembaca dan dapat juga dijadikan bahan atau salah satu referensi bagi peneliti lain yang melakukan penelitian sejenis ataupun lanjutan mengenai nilai budaya dan nilai moral dalam tradisi (lisan) muayak pada acara sunatan masyarakat Banding Agung OKU Selatan.

\section{DAFTAR PUSTAKA}

Aminuddin. (2010). Pengantar Apresiasi Karya Sastra. Bandung: Sinar Baru.

Endraswara, Swardi. (2008). Metodologi Penelitian Sastra: Epistemologi, Model, Teori, dan Aplikasi. Yogyakarta: Media Pressindo.

Herimanto, dkk. (2008). Ilmu Sosial Budaya Dasar. Solo: Bumi Angkasa.

Kosasih, E. (2012). Dasar-dasar Keterampilan Bersastra. Bandung: Yrama Widya.

Mahyana, Maman. (2005). Sembilan Jawaban Sastra Indonesia. Jakarta: Bening.

Mangkuprawira, Safri. (2006). Kajian Etika dan Filsafat Komunikasi. Yogyakarta: Widya Duta.

Nurhayati. (2012). Pengantar Ringkas Teori Sastra. Yogyakarta: Media Perkasa.

Nurgiyantoro. H.G. (2010). Teori Pengkajian Fiksi. Yogyakarta: Gajah Mada Universitas Pers.

Sugiyono. (2013). Metode Penelitian Kuantitatif Kualitatif Dan $R \& D$. Bandung: Alfabeta.

Surakhmad, Winarno. (2004). Pengantar Penelitian Ilmiah: Dasar Metode Teknik. Bandung: Tarsito.

Zaidan, dkk. (2007). Kamus Istilah Sastra. Jakarta: Balai Pustaka. 